Acta Crystallographica Section D

Biological

Crystallography

ISSN 0907-4449

Joanne E. Nettleship, Thomas S. Walter, Robin Aplin, David K. Stammers and Ray J. Owens*

Oxford Protein Production Facility, Wellcome Trust Centre for Human Genetics, Roosevelt Drive, Oxford OX3 7BN, England

Correspondence e-mail: ray@strubi.ox.ac.uk

Received 8 November 2004

Accepted 7 March 2005

\section{Sample preparation and mass-spectrometric characterization of crystal-derived protein samples}

\begin{abstract}
Mass spectrometry is often used to ascertain the accurate mass of purified protein samples prior to crystallization screening. However, in many cases data regarding the form of the protein crystallizing can also be useful, as this may differ from the original sample. Development of a simple method for the preparation and mass spectrometry of crystal-derived protein samples is described. The method is exemplified by the determination of the phosphorylation state of protein in a crystal derived from a mixture of phosphorylated and unphosphorylated protein.
\end{abstract}

\section{Introduction}

Mass spectrometry is often used as a quality-control step to measure accurately the mass of a protein sample prior to crystallization. However, this may not correspond to the mass of the protein which subsequently crystallizes (for a review, see Cohen \& Chait, 2001). This is especially relevant if crystals appear after degradation of a protein sample or if the initial sample contains more than one form of the same protein. Protein-degradation products could be identified by comparison of the accurate mass of the crystal-derived sample with the theoretical masses of possible truncations. In such cases, knowledge of the accurate mass of protein present in the crystal can be used to aid structure solution and also functional assignment.

In this report, we describe a simple method for characterization of protein crystals by mass spectrometry which is independent of crystallization condition. The protocol was developed using crystallized lysozyme as a model system and then applied to crystals of a protein of unknown structure, yielding results which were useful in interpreting its structure.

\section{Materials and methods}

\subsection{Preparation of crystals for mass spectrometry}

Lysozyme (Sigma-Aldrich, Poole, England) crystals were produced using the formulation described by Ducruix \& Giegé (1999) and implemented in nanolitre drops using the method of Walter et al. (2003, 2005). The foil seal covering the crystallization plates was pierced with a syringe needle and the plate covered between manipulations to prevent evaporation of the drops. The mother liquor was first removed from around the crystal by wicking (extra fine long paper wicks; Hampton Research, CA, USA). The crystal was washed with $5 \mu \mathrm{l}$ reservoir solution followed by $2 \times 5 \mu$ l acetonitrile. Any excess liquid remaining in the wells was removed by wicking before dissolving the crystal in $10 \mu \mathrm{l} 20 \mathrm{mM}$ Tris $\mathrm{pH} 7.5$, $200 \mathrm{~m} M \mathrm{NaCl}, 8 M$ urea buffer.

\subsection{LC-ESI-MS}

LC-ESI-MS was performed using an Ultima HPLC (Dionex, Camberley, England) connected to a Q-TOF (Quadrupole Time-ofFlight) Micromass spectrometer (Waters, Manchester, England) which is accurate to within $1 \mathrm{Da}$ for intact protein samples. Samples were automatically loaded through an autosampler onto a reversephase C4 pre-column (Anachem, Luton, England). The pre-column was washed to waste with $99 \%$ water $/ 1 \%$ formic acid to remove salts 
before elution of the protein to ESI-MS using $80 \%$ acetonitrile/20\% water containing $0.1 \%$ formic acid.

\section{Results}

\subsection{Method development}

The mass spectra of several similarly sized $\left(0.02 \mathrm{~mm}^{3}\right)$ lysozyme crystals were measured in order to investigate the effect of crystallization condition on the ability to obtain usable mass spectra of crystal-derived protein samples. Sizing of crystals was performed by comparison to the well proportions of the crystallization plate (Mayo et al., 2005). Initially, washing of crystals was carried out with the reservoir solution only. The washing was performed within the well of the crystallization plate in order to minimize manipulation of the crystal. A clean mass spectrum could be readily obtained if the crystallization drop only contained ionic and inorganic components (Fig. 1a). However, if the crystallization condition contained detergents or PEG, the resulting data were less satisfactory owing to the large PEG envelope between $\mathrm{m} / z=600$ and $\mathrm{m} / z=1250$ (Fig. $1 b$ ). Although the lysozyme-ion series is well resolved in Fig. 1(b), this may not be the case for other proteins. As PEG is a common precipitant used in crystallization, use of acetonitrile washing was investigated. By performing two washes, PEGs of different molecular weight (e.g. PEG 3000 and PEG 8000) could be almost totally removed from the samples to give clean accurate results (Figs. $1 c$ and $1 d$ ). Attempts to wash lysozyme crystals with other organic solvents led to destruction of the crystal. To test the effectiveness of washing to remove non-crystallized protein, crystals of lysozyme were grown in drops containing a similarly sized (14 $790 \mathrm{Da})$ non-crystallizing protein contaminant: OPPF2067. Before crystallization, the mass spectrum of the protein solution could be seen to contain both lysozyme and OPPF2067 (Fig. 2a). However, after preparation of the lysozyme crystals the non-crystallizing contaminant could not be detected (Fig. 2b). Therefore, washing once with reservoir solution and twice with acetonitrile can be seen to reduce non-crystallized protein, detergent and polyethylene glycol (PEG) in the sample to undetectable levels.

\subsection{Mass spectrometry of crystal-derived OPPF target protein}

Mass spectrometry of crystal samples in the Oxford Protein Production Facility (OPPF) can be exemplified by target 697 , NMB0736, a nitrogen-regulatory protein from Neisseria meningitidis (hereafter referred to as OPPF697). Prior to crystallization, LC-ESIMS revealed the presence of both phosphorylated and unphosphorylated forms of OPPF697 (Fig. 3a). The unphosphorylated OPPF697 mass correlates with the expected mass calculated from the protein sequence and the phosphorylated mass corresponds to this mass plus one phosphoryl group. After crystallization screening using the method of Walter et al. $(2003,2005)$, crystals were obtained in various conditions (Fig. $3 b$ ). The phosphorylation state of the crystallized protein was not known; hence, crystals were taken for massspectrometric analysis. A major peak at $16246 \mathrm{Da}$ was observed by LC-ESI-MS of an OPPF697 crystal corresponding to unphosphorylated protein (Fig. 3c). The minor peak at 16288 Da arises from carbamylation of the protein during preparation with urea (Stark, 1965). The finding that only crystals of unphosphorylated OPPF697

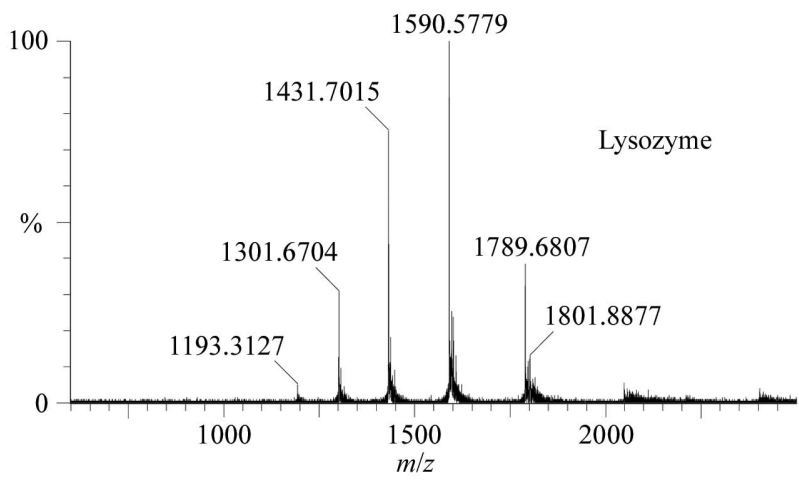

(a)

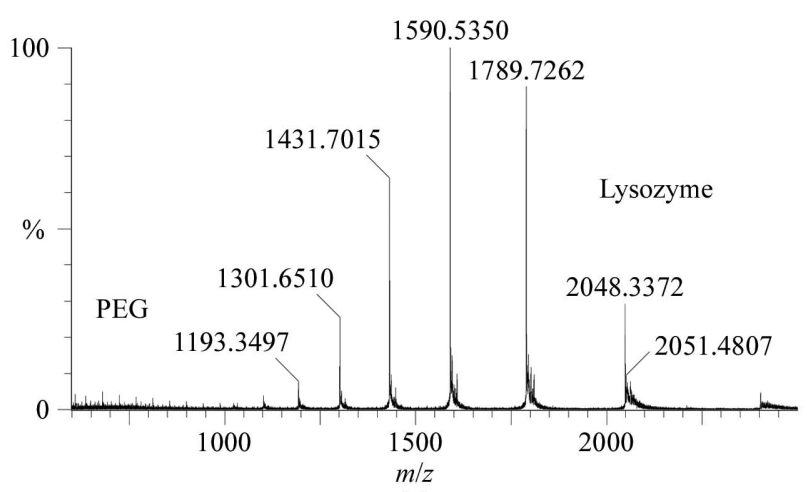

(c)

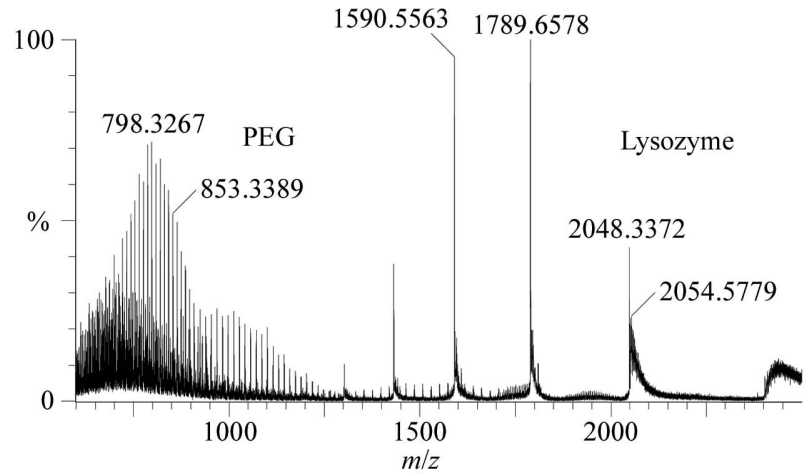

(b)

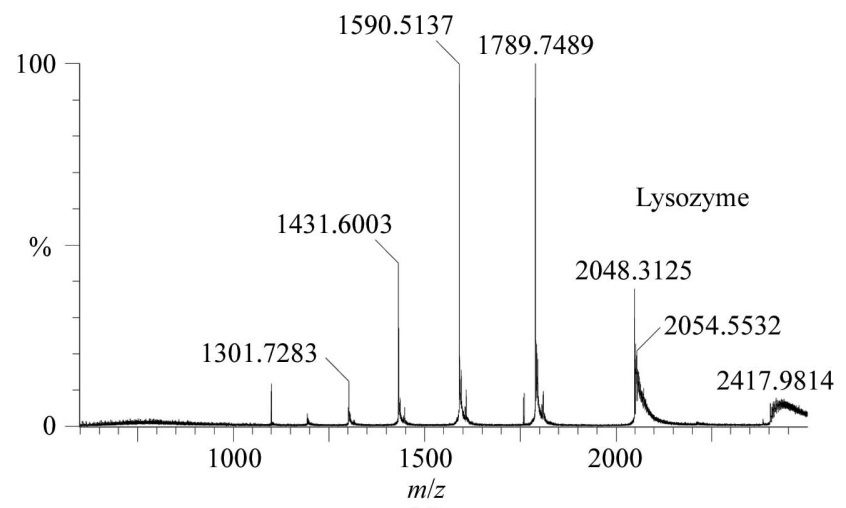

(d)

Figure 1

Raw ESI-MS data obtained from lysozyme crystals from differing crystallization conditions. (a) Crystal grown in $0.2 \mathrm{M}$ magnesium chloride, $0.1 \mathrm{M}$ imidazole $\mathrm{pH} 8,15 \%$ ethanol and prepared by reservoir-solution washing only (total ion current, TIC $\left.=1.30 \times 10^{3}\right)$. (b) Crystal grown in $10 \%$ PEG $3000,0.2 \mathrm{M}$ lithium sulfate, $0.1 \mathrm{M}$ imidazole $\mathrm{pH}$ 8 and prepared by reservoir-solution washing only $\left(\right.$ TIC $\left.=1.32 \times 10^{3}\right)$. $(c)$ Crystal grown in $20 \%$ PEG 3000, $0.2 M$ calcium acetate, $0.1 M$ Tris pH 7 and prepared by reservoirsolution and $2 \times$ acetonitrile washing $\left(\mathrm{TIC}=1.36 \times 10^{3}\right)$. $(d)$ Crystal grown in $20 \%$ PEG 8000, $0.2 M$ magnesium choloride, $0.1 M$ Tris $\mathrm{pH} 8.5$ and prepared by reservoirsolution and $2 \times$ acetonitrile washing (TIC $\left.=3.66 \times 10^{3}\right)$. 


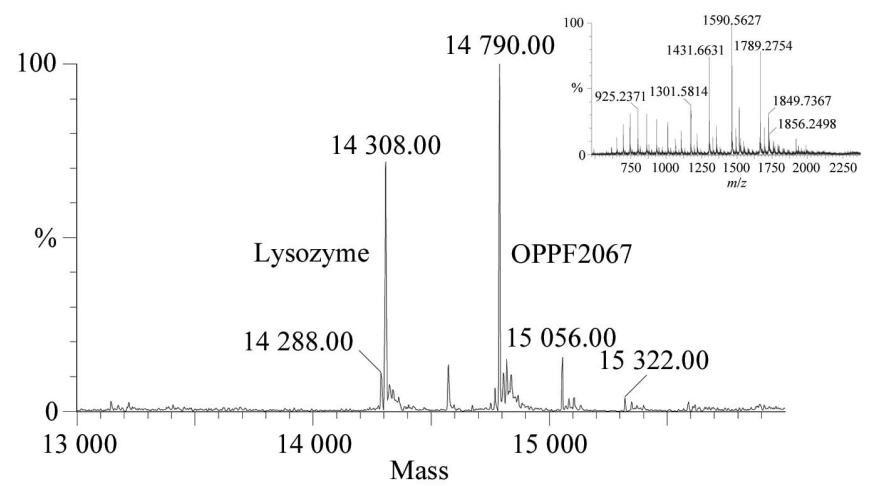

(a)

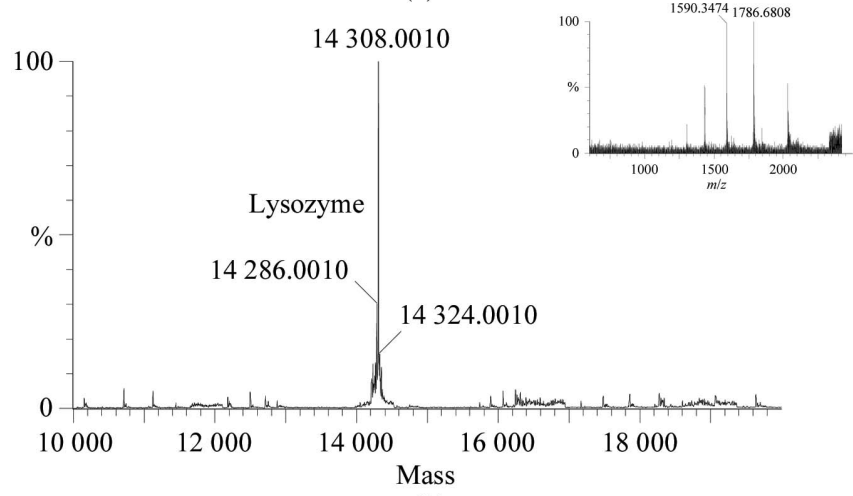

(b)

Figure 2

(a) Raw ESI-MS data $\left(\right.$ TIC $\left.=3.12 \times 10^{4}\right)$ and deconvoluted mass spectrum of lysozyme contaminated with OPPF2067 prior to crystallization. (b) Raw ESI-MS data $\left(\right.$ TIC $\left.=7.56 \times 10^{3}\right)$ and deconvoluted mass spectrum of crystal-derived lysozyme sample with contaminating protein removed. Crystal grown in $20 \%$ PEG $8000,0.2 \mathrm{M} \mathrm{MgCl}_{2}, 0.1 M$ Tris $\mathrm{pH} 7.5$ and prepared by reservoir-solution and $2 \times$ acetonitrile washing.

had been obtained was subsequently confirmed by the determination of the structure of OPPF697 (Ren, Sainsbury, Berrow, Alderton, Nettleship, Stammers, Saunders \& Owens, unpublished results).

\section{Discussion}

The crystallization conditions and the concentration of protein in a crystal can provide obstacles to obtaining satisfactory mass spectra of protein samples derived from crystals. Potier et al. (2000) describe a protocol which solves the first of these problems but requires a great deal of crystal handling. We have devised a simpler method which does not require removing the crystal from the crystallization plate but which nevertheless removes all traces of the mother liquor. The concentration of protein in the crystal sample remains a limitation as this is dependent on both crystal size and the molecular mass of the protein; however, we have demonstrated that reliable data can be obtained from crystals grown in nanolitre drops.

We are grateful to Nick Berrow, David Alderton and Sarah Sainsbury for supply of OPPF697 and to Karl Harlos and Dave Stuart for discussions. The work described here was supported by the MRC and the European Commission as SPINE contract No. QLG2-CT2002-00988.

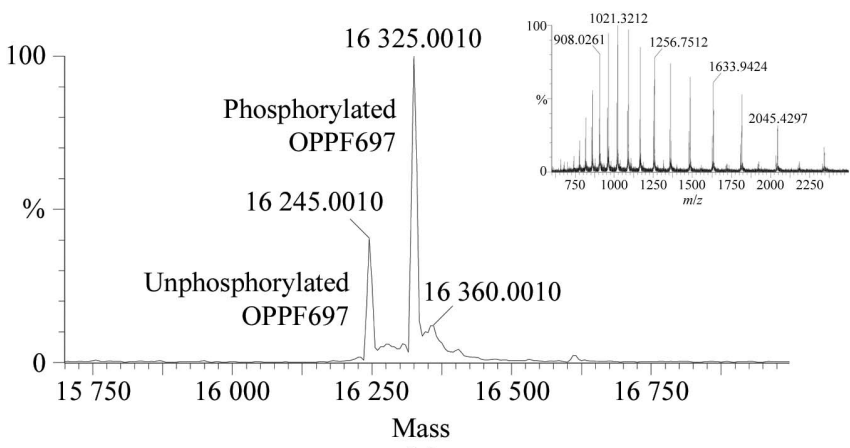

(a)

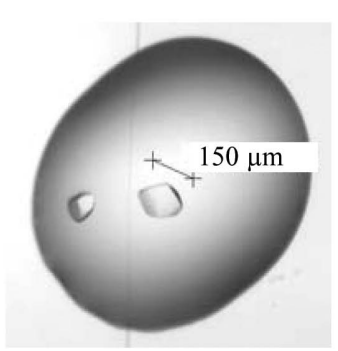

(b)

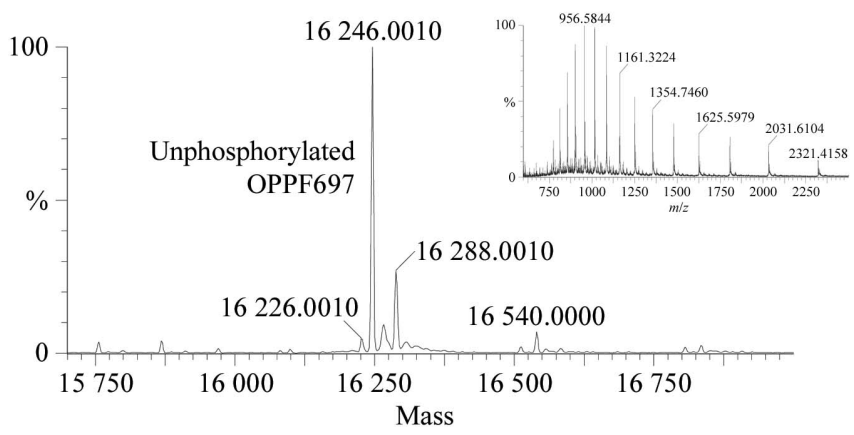

(c)

Figure 3

(a) Raw ESI-MS data $\left(\right.$ TIC $\left.=4.33 \times 10^{4}\right)$ and deconvoluted mass spectrum of OPPF697 purified protein prior to crystallization. The N-terminal $\mathrm{His}_{6}$ tag was removed by proteolytic cleavage during purification. (b) Image of OPPF697 crystal taken for mass-spectrometric analysis, which was grown in $0.1 \mathrm{M}$ citrate $\mathrm{pH} 5,3.2 \mathrm{M}$ ammonium sulfate. $(c)$ Raw ESI-MS data $\left(\right.$ TIC $\left.=3.38 \times 10^{5}\right)$ and deconvoluted mass spectrum of crystal-derived protein sample prepared by reservoir-solution and $2 \times$ acetonitrile washing.

\section{References}

Cohen, S. L. \& Chait, B. T. (2001). Annu. Rev. Biophys. Biomol. Struct. 30, 6785.

Ducruix, A. \& Giegé, R. (1999). Crystallization of Nucleic Acids and Proteins, pp. 130-137. Oxford University Press.

Mayo, C., Diprose, J. M., Walter, T., Berry, I., Wilson, J., Owens, R. J., Jones, E. Y., Harlos, K., Stuart, D. I. \& Esnouf, R. M. (2005). Structure, 13, 341-353. Potier, N., Lamour, V., Poterszman, A., Thierry, J. C., Moras, D. \& Van Dorsselaer, A. (2000). Acta Cryst. D56, 1583-1590.

Stark, G. R. (1965). Biochemistry, 4, 1030-1036.

Walter, T. S., Diprose, J., Brown, J., Pickford, M., Owens, R. J., Stuart, D. I. \& Harlos, K. (2003) J. Appl. Cryst. 36, 308-314.

Walter, T. S., Diprose, J. M., Mayo, C. J., Siebold, C., Pickford, M. G., Carter, L., Sutton, G. C., Berrow, N. S., Brown, J., Berry, I. M., Stewart-Jones, G. B. E., Grimes, J. M., Stammers, D. K., Esnouf, R. M., Jones, E. Y., Owens, R. J., Stuart, D. I. \& Harlos, K. (2005). In the press. 